\title{
Operationalized Multi-Stakeholder Strategic Road-Mapping for Small-to-Medium Nonprofit Organizations
}

\author{
Dan Tenney, Nasir Jamil Sheikh \\ Technology Management Department, The University of Bridgeport, Bridgeport, USA \\ Email: dan.tenney@outlook.com,nsheikh@bridgeport.edu
}

How to cite this paper: Tenney, D., \& Sheikh, N. J. (2020). Operationalized Multi-Stakeholder Strategic Road-Mapping for Small-to-Medium Nonprofit Organizations. Open Journal of Business and Management, 8, 2559-2581.

https://doi.org/10.4236/ojbm.2020.86159

Received: September 15, 2020

Accepted: November 15, 2020

Published: November 18, 2020

Copyright $\odot 2020$ by author(s) and Scientific Research Publishing Inc. This work is licensed under the Creative Commons Attribution International License (CC BY 4.0).

http://creativecommons.org/licenses/by/4.0/

\begin{abstract}
Long-term strategic planning is not typical among small-to-medium nonprofit organizations (SMNOs), and their focus tends to be towards tactical mission priorities. This prioritization is due to limited resources and capabilities, although a strategic plan is still considered important for the nonprofit social enterprise's sustained viability. This research develops a visual strategic roadmap (SRM) model that could be the basis for a long-term strategy for such nonprofits. This roadmap model includes lanes that represent multiple stakeholder perspectives and may be used to identify the policies and procedures required to achieve the long-term vision. Road-mapping fulfills a strategic planning need for nonprofit organizations, especially SMNOs, which in most cases, is absent. The perspectives covered are Social, Technical, Economic, Environmental, and Political (STEEP). A strategic roadmap model is validated using expert judgments and by the case study of a small-to-medium mental health nonprofit organization agency located in Southeastern Connecticut. The SRM validation revealed a model that is easy to visualize, and future work will verify its effectiveness.
\end{abstract}

\section{Keywords}

Strategic Planning, Strategic Road-Mapping, Small Medium Nonprofit Organizations, Continuous Improvement, Delphi Method

\section{Introduction}

Nonprofit organizations may not remain viable to their mission and vision unless they sustain an effective strategic management framework with appropriate longer-term planning and execution (Hu, Kapucu, \& O'Byrne, 2014). Strategic 
management refers to the process of continuous planning, monitoring, analysis, and assessment into the future to meet its goals and objectives. Small-to-medium nonprofit organizations (SMNOs) continue to experience notable changes based on a series of strategy-related studies that find nonprofits expanding in numbers as government support diminishes (Maier, Meyer, \& Steinbereithner, 2016). A systematic literature review of nonprofit strategy spanning from the 1980s to the present confirms this finding (Laurett \& Ferreira, 2018). A strategic roadmap (SRM) is a viable model that can be utilized to develop a strategic plan as part of the strategic management process. Strategic planning is the process of identifying priorities and goals necessary to meet the SMNO mission. This process may be less straightforward than planning for the profit sector (Jarzabkowski \& Kaplan, 2015). The SRM is a time-based strategic planning methodology. It is widely used to develop a plan that is a visual representation of where the organization is or has been in addition to a forecast to where it is heading along a pathway of its vision. SMNOs need to develop specific strategic plans based on the individual functions within their mission area. Strategic planning fills a critical role in a continuous improvement process. All organizations should continuously improve their processes to sustain their viability. To ensure organizational sustainability, many other continuous improvement techniques were also examined in the literature. Out of these, Capability Maturity Model Integration (CMMI) (Abdel-Hamid \& Hamouda, 2015; Dounos \& Bohoris, 2010) used in the software industry, and Total Quality Management (TQM) (Lewis, Pun, \& Lalla, 2006; Sweis et al., 2016) used in multiple applications are two frequently used improvement techniques. SRM for SMNOs differentiates itself from other methodologies by being one of the most effective best practice strategic planning improvement techniques. For instance, CMMI and TQM are continuous improvement methodologies which focus on immediate opportunities. These opportunities may have longer-term implications, but these improvement processes do not specifically define forecasted periods for future improvement. The SRM strategic planning model, on the other hand, provides a mechanism to evaluate past practices, the current environment, and plan into a predetermined period typically up to five years into the future, in order to determine what the future vision may look like. The strategic planning functions require an in-depth review of the elements that compose the organization and form the improvement process. Determining these elements requires knowledge from those involved in the process that is promoted through strategic thinking, acting, and learning (Bryson, 2010).

With this knowledge of the critical SMNO elements, important organizational questions are determined for SMNO strategic planning. These questions were validated by experts in the SMNO key functions and then answered by these same experts (Grant \& Davis, 1997) by three separate questionnaires. In the first questionnaire, questionnaire 0 , data will help form the basis of the SMNO SRM. The proposed SRM, along with predetermined decision-making criteria, will form the basis of a viable SRM framework. Such framework may be used to de- 
termine individual strategic planning as part of the SMNOs strategic management process. Policies and procedures may be developed from the components of this framework. The result is a strategic framework that determines plan milestones and potential policies and procedures to secure the SMNO SRM framework. For the other two questionnaires, questionnaires 1 and 2, the expert judgment validates the elements that are necessary to implement an SRM.

The research was designed and developed from the need that the author determined while acting as a Board of Director member on a SMNO. The topic became the author's independent dissertation research at the University of Bridgeport, CT. USA. The SRM model was expanded from a traditional Technology Road-Mapping model. The research validated the need and the SRM model's uniqueness in application.

The remainder of this article includes a description of the research methods which integrate a summary of the literature on strategic road-mapping, an SRM model validation using expert questionnaire feedback including results of the feedback, methodology evaluation of the SMNO SRM, and the construction of key definitions within the SRM perspective framework and model. Lastly, a case study was used to draw expert feedback information from a separate questionnaire which was used to help validate the SRM.

\section{Literature Review}

The development of an SRM for an SMNO required a thorough review of the literature to establish what work has been conducted in this area and usage of the literature search to establish an SRM framework. Today's changing societal environment requires improved strategic management and support to sustain the long-term viability of SMNOs. Addressing a variety of gaps in the literature pertaining to longer-term strategic planning, this study contributes to the related literature by:

1) Introducing a novel SRM model that addresses the specific needs of SMNOs for the first time.

2) Providing real-life validation data for the formation of an SRM SMNO framework.

3) Introducing real data to the related literature given that the majority of SMNOs are not public entities with their data being unavailable to the public.

4) Highlighting the importance of stronger and more progressive committees for the long-term sustainability of nonprofit organizations.

This is the first study that applies high-level strategic roadmap (SRM) modeling to small-to-medium nonprofit organizations (SMNOs). In this regard, an SRM model is developed and validated to provide a basis for long-term SMNO strategic planning that is critical in supporting an organization's mission-critical viability.

The literature review included over 150 journal articles and books. Out of these, 74 pertinent journal articles were cited relating to the three key nonprofit 
perspectives, viz., market trends (13), operations (39), and road-mapping (22). Multiple search databases, including Pubmed, SpringerLink, Sage, ABI/Inform, Google Scholar, Wiley On-Line, ProQuest, Taylor \& Francis Social Science, Elsevier Science Direct, and EBSCO were utilized to search for the three key nonprofit perspectives. Keyword searches included strategic planning, road-mapping, nonprofit, continuous improvement, and nonprofit market trends.

The literature review is designed to study the related body of work to gain knowledge of the status of the three core aspects listed in Figure 1. The gap of the intersection of nonprofit organizational road-mapping, market trends, and operational aspects provides the intersection of the body of this work's research and the focal point of this paper.

Nonprofit organizations do not have abundant managerial resources and experience, especially the small-to-medium nonprofit organizations (SMNOs), and the resources that they do possess, must be managed more efficiently and effectively to attain their mission and vision (Laurett \& Ferreira, 2018). Therefore, the development of a strategic management process that would assist these organizations to create the appropriate planning, structure, policy, and procedures to accomplish longer and more effective planning is necessary. This approach creates a better scenario that emulates more robust management strategies of for-profit organizations (Sanders \& McClellan, 2014). Strategic management may be defined as "the appropriate and reasonable integration of strategic planning and implementation across an organization (or other entity) in an ongoing way to enhance the fulfillment of its mission, meeting of mandates, continuous learning, and sustained creation of public value" (Bryson, 2010). Nonprofit organizations may be heading towards irrelevance or bankruptcy if they do not reshape themselves with a more efficient and effective strategic management framework (Marc, 2001; Mihm, 2011). Strategy planning for nonprofits is almost mandatory these days, and choosing an effective process such as road-mapping, including technology road-mapping and strategic planning, is critical (Phaal, Farrukh, \& Probert, 2001). A strategic roadmap provides a visual strategy for mapping nonprofit organizations (Bryson, Eden, \& Ackermann, 2014).

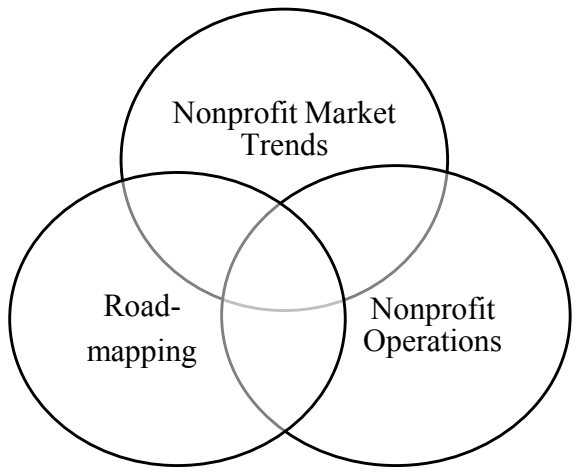

Figure 1. Road-mapping Improvement Intersection. 
Nonprofit organizations' operational aspects focus on improvement mechanisms and resulting policies and procedural governance necessary to control and sustain the nonprofit enterprise. Nonprofit operations delved into the critical aspects of nonprofit strategic operations and the various continuous improvement areas that have been utilized over the last 25 to 30 years. To survive, nonprofit organizations must operate in a more business-like fashion (A. \& J., 1998; Maier et al., 2016; Sanders \& McClellan, 2014; Topor \& Boroiu, 2011; Wymer \& Alves, 2013). Nonprofit strategic management effectiveness is hard to quantify. Such limitation partially explains why it is more difficult to administer than a for-profit management strategy (Lecy, Schmitz, \& Swedlund, 2012).

Market trends explore what was necessary to understand the nonprofit market's needs and the fact that nonprofit organizations have increased by $40 \%$ to $50 \%$ in the last generation (Harrison \& Thornton, 2014; Kim, 2015). Market trend aspects of nonprofit organizations revealed details of the types and increasing numbers of nonprofit organizations in operation. There are more than 1,600,000 nonprofit organizations in the United States today (Gratton, 2018). This number doubled between 1995 and 2014 (Harrison \& Thornton, 2014). There are multiple types of nonprofit organizations, and each organization has its mission and guidance criteria. Types of nonprofit organizations may include charities, health services, religious affiliation, trade unions, welfare societies, and similarly related organizations. Charities, educational or religious are the most common types of nonprofit organizations. There are 1,400,000 nonprofit organizations that fall into a government classification referred to as a 501(c) 3 which must adhere to strict governance rules to maintain this tax-favored government status (Phillips et al., 2019).

The related literature that focuses on road-mapping is quite limited. Road-mapping is defined as a method that can serve as a model that can unveil the unique needs of a nonprofit that must be sustained and adapted over a forecasted time period (Seyed Amir \& Reiche, 2013).

SMNOs have limited resources and must effectively and efficiently manage those resources to attain their missions (Tenney \& Sheikh, 2019). There has been an increase in nonprofit organizational strategic planning publications in multiple geographical locations since 2010 relative to those published from the $1980 \mathrm{~s}$ to 2010 (Laurett \& Ferreira, 2018). Therefore, developing a strategic management process that would assist these organizations in creating the appropriate planning, structure, policy, and procedures to accomplish longer and more effective planning is necessary. Such an approach creates a better scenario that emulates more robust management strategies of for-profit organizations (Sanders \& McClellan, 2014). Strategic management may be defined as "the appropriate and reasonable integration of strategic planning and implementation across an organization (or other entity) in an ongoing way to enhance the fulfillment of its mission, meeting of mandates, continuous learning, and sustained creation of public value" (Bryson, 2010). Therefore, strategic planning for nonprofits is be- 
coming essential, and choosing an effective process such as road-mapping, including technology and strategic planning, can facilitate this process (Bryson, 2010; Phaal, Farrukh, \& Probert, 2004; Willyard \& McClees, 1987).

Nonprofit organizations benefit when they apply strategic planning (Bryson, 2010; Giffords \& Dina, 2004). The goal of a nonprofit organization is to meet its mission. This objective can be less quantifiable and requires a unique set of skills (Sanders \& McClellan, 2014). These skills and the lack of overall human resources may hinder strategic planning. Strategic road-mapping is a specific subset of a strategic planning method that is not familiar to the nonprofit world. Perspectives in the SMNO community are linked to connection areas that include Social, Technical, Economic, Environmental, and Political (STEEP).

The multiple perspectives of STEEP affect the nonprofit organization's long-term planning and viability. Harold Linstone (1981) was a pioneer in evaluating technologies that used multiple perspectives (Linstone, 1981). SMNOs typically use social and economic perspective aspects in their quest for sustainability. However, environmental and technical perspectives are an essential auxiliary area to aid daily operations and ensure a safe and efficient environment. Political perspective is vitally important in regulatory and risk management areas to assure SMNO viability and sustainability. Linstone stated that by considering multiple perspectives such as STEEP, an SRM for SMNOs can improve decision-making by providing a more balanced decision-making outcome (Linstone, 2000).

\section{Method}

A qualitative research methodology was used to develop the strategic road-mapping (SRM) model. In its final form, a strategic roadmap is a visual representation of themes or initiatives on distinct swim-lanes. It includes past and current states, long-term goals or aspects of the vision, and future steps or milestones to implement an organizational strategy. A foresight modeling framework based on technology road-mapping was initially constructed from a structured literature review that helped to define the main roadmap swim-lanes and elements. The literature search revealed the significance of road-mapping and its value in nonprofit organizations' strategic planning process. Since road-mapping was being applied to strategies for nonprofit organizations, their strategic and operational priorities were also researched. The strategic roadmap framework was further developed into a model by utilizing expert judgments via a modified Delphi method (Skulmoski, Hartman, \& Krahn, 2007). The Delphi method is a forecasting or assessment process based on multiple rounds of questionnaires representing research instruments sent to a panel of experts (Hsu \& Sandford, 2007; Linstone \& Turoff, 2011). In this case, the first set of questions goal was to develop a strategic roadmap framework that was valid for small-to-medium nonprofits. A second set of questions was for the expert decision-makers of SMNOs to validate the top-level swim-lane elements and their priorities along 
with the strategic planning and forecasting process. The third set of questions provided an SRM implementation plan for a case study that operationalized the strategic roadmap by linking the top-level strategic elements to specific practitioner-based tasks. The Delphi method should be considered for social researchers, community practitioners, and policymakers (Brady, 2015), such as in SMNO research. This modified Delphi method utilized a web survey that contained Likert (5 level ranking measures of importance) scale questions for two of the surveys. The computer-aided questionnaires shortened the participation and analysis process since they included tools that aided analysis. It has been stated that a modified Delphi method can increase the speed of data transmission, improve the ability to analyze the questionnaire information, and increase participant confidence in the questionnaire process (Hartman \& Baldwin, 1995).

Each questionnaire expert judgment feedback built a validation stage that leads to the SRM framework that was developed. Figure 2 depicts the process of modeling the strategic roadmap process. The modeling progresses from the SMNO SRM framework assessment into the development of the perspectives and their criterion, functions, and task element outcomes. The validation of the strategic roadmap framework with expert judgment, taxonomy definitions of these elements, and case application leads to the results and conclusions.

Strategic road-mapping is a forecasting tool that leads to decision analysis. Multi-Criteria Decision Analysis (MCDA) has been applied to many applications. Analytic Hierarchy Process (AHP) is one popular MCDA tool introduced in the 1970s by Thomas Saaty (Saaty, 2008) that has application potential for this research. Others, such as Chen and Kocaoglu (Chen \& Kocaoglu, 2008), have applied a similar variant of AHP to road-mapping called Hierarchical Decision Making (HDM). HDM is a multi-level assessment methodology that methodically helps to determine elements of the roadmap. Combining HDM with road-mapping can lead to a better decision-making process, given the capability to better analyze multiple decisions that the road-mapping may present. For this model, a multi-level variant of the HDM framework was applied to provide structure to the Hierarchy of Roadmap Elements, as shown in Figure 3.

\subsection{Questionnaire Process}

The modified Delphi method was used to validate the SRM model. The Delphi Method is a structured communication technique originally developed as a systematic interactive forecasting method that relied on experts' panel. Typically, the experts answered two or more rounds of questionnaires.

The results were tabulated and analyzed using a qualitative decision-making method to create the finished consolidated SRM framework model. Even though the experts possessed multiple backgrounds, they met the criteria that were required to provide expert validation judgment. They had to be real experts in their field on nonprofit management, have the capacity and willingness to participate in the survey questionnaire, and effectively communicate and defend 


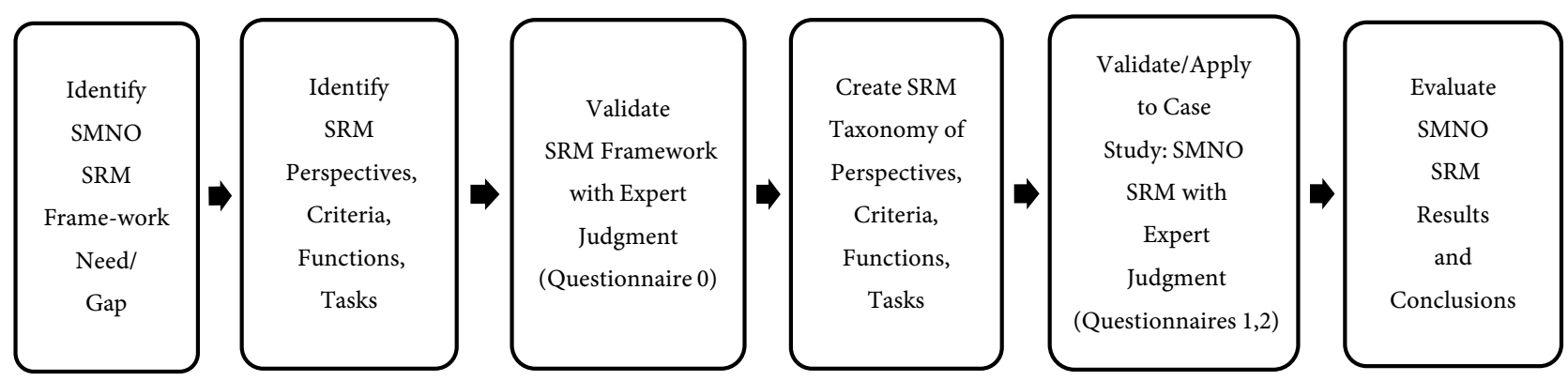

Figure 2. Strategic Road-mapping Research Process.

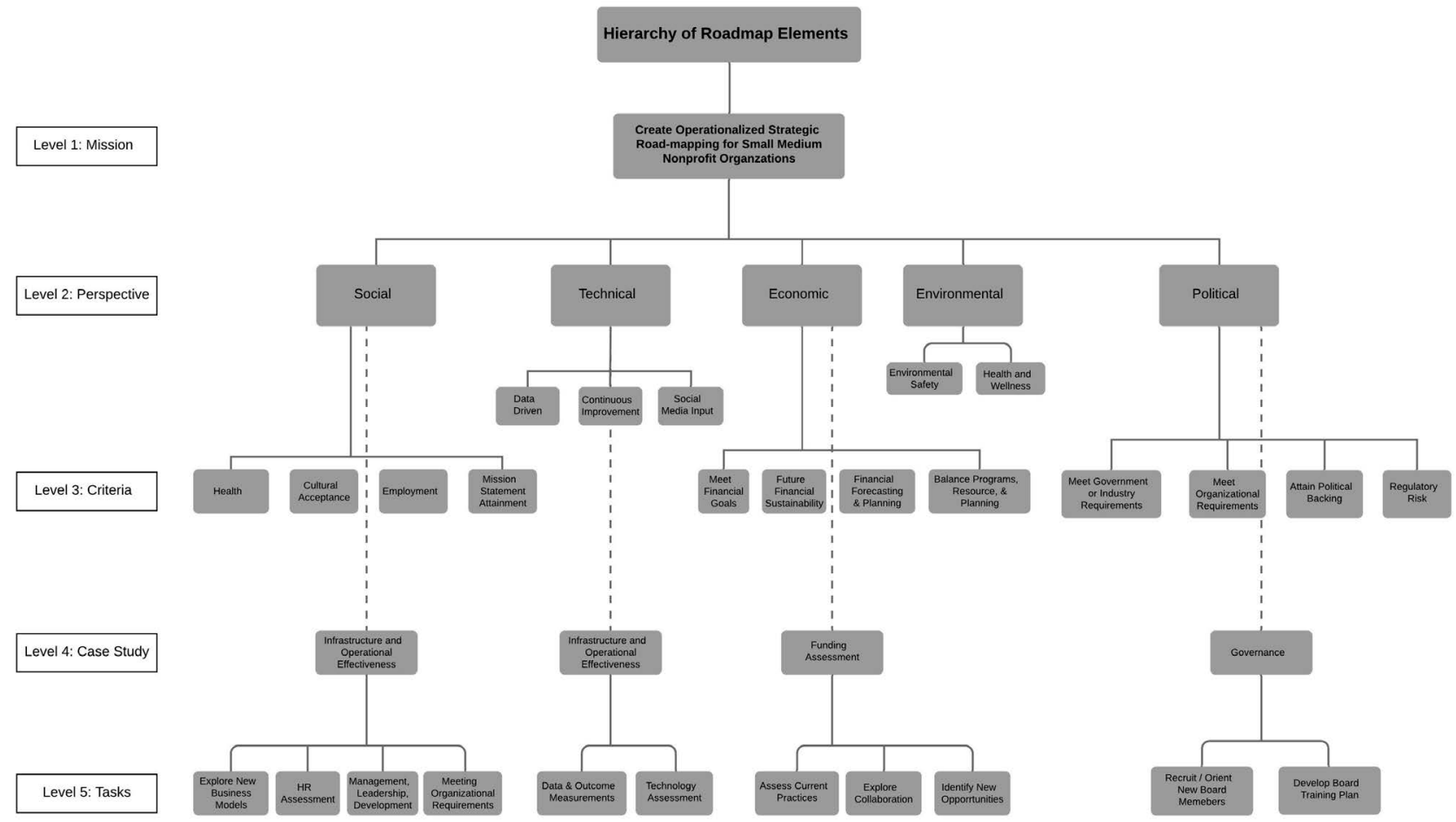

Figure 3. Hierarchy of strategic Road-Mapping elements.

their questionnaire feedback (Skulmoski, Hartman, \& Krahn, 2007). The questionnaires were anonymous with direct interviewing contact as a final process step. Questionnaires ( 1 and 2 ) had open access to the online questionnaires. The experts had to be willing to participate in a validation process that required more than 20 responses each in 5 perspectives (STEEP) for questionnaire 0 and 11 responses for each of the other two questionnaires (1 and 2). The questionnaire processes were accepted as a compliant Internal Review Board (IRB) process. Snowballing was used to build the respondent base for the study. This technique was based on word of mouth references, and in many cases, required an introduction from the willing participant to their recommended participant. Willingness to help their cause created a more engaged and willing participant. Lastly, it was almost always necessary to meet in person to gather the richest feedback. However, the Covid-19 pandemic modified the contact to video con- 
ferencing, email correspondence, or phone for questionnaires 1 and 2. The process of requesting support lent a 3 to 1 factor of participation response even with this direct referral method. Ultimately, nine key experts participated in questionnaire 0, 14 experts participated in questionnaire 1, and 11 experts participated in questionnaire 2 from a total list of 34 potential experts. Some of the experts participated in more than one of the questionnaires. A consensus approach was used to finalize the questionnaire input interpretation. There were no significant disagreements accept when there was a range of opinions on the length of planning intervals. A consensus among the experts was reached. Clear definitions and taxonomy of the questions' elements were created to avoid misunderstanding or misinterpretation of the questions. Making the definitions more precise and direct interaction served to clarify questions and to alleviate disagreements among the experts. Disagreements were found to be based on the need for more information than was provided and was resolved with further discussion and clarification. The experts' sample size was appropriate based on their background and desired experience with nonprofit management and planning (Grant \& Davis, 1997). In this validation process method, the experts must have nonprofit organization experience and an understanding of the STEEP perspectives in this area.

Table 1 depicts the questionnaire expert background information on the 14 direct respondents for all three questionnaires.

The contents of the three questionnaires in addition to their summary are provided in Table 2.

\subsection{SMNO Strategic Perspectives and Road-Mapping Framework: A Case Study}

A mental health nonprofit agency for children was chosen to help validate the SRM framework. The agency's mission is stated as "We provide children and families with culturally-informed mental health care and complementary supports, regardless of ability to pay." The organization resides in Southern Connecticut between New York City and Boston. They currently operate with approximately 125 full-time staff members and a maximum of one dozen interns. Their core competencies include social work and psychotherapy, including casework with in-patient and out-patient care. Their capacity to perform longer-range planning and process improvement is limited because of their lack of resources and know-how beyond servicing their mission. Validation of the research SRM framework was assisted by several key staff members, including the CEO and the Compliance Director. The overall SRM framework can be applied but linking it to the task level needs to be specific to the case study. The tasks that were generated in the SRM framework were a result of the strategic planning process. This strategic planning process was formed with input from the Board of Directors and the Leadership team in 2019. 
Table 1. The Background Information on Hi-level Nonprofit Leaders; 34 Total Pool/ Experts Background.

\begin{tabular}{|c|c|c|c|c|c|}
\hline Expert \# & Roles & $\begin{array}{l}\text { Qualification: } \\
\text { Years of Experience }\end{array}$ & $\begin{array}{l}\text { Qualifications: } \\
\text { Areas of Specialty }\end{array}$ & Areas of Interest & $\begin{array}{l}\text { STEEP Area } \\
\text { Covered }\end{array}$ \\
\hline & $\begin{array}{l}\text { CEO, Executive Director, } \\
\text { Sr VP, Partner, Chief } \\
\text { Legal Counsel, CFO, and } \\
\text { Directors }\end{array}$ & $\begin{array}{l}\text { Average experience } \\
\text { is }>10 \text { years; the range } \\
\text { is } 10 \text { - } 35 \text { years }\end{array}$ & $\begin{array}{l}\text { Nonprofit: Governance, } \\
\text { Leadership, Social Service, } \\
\text { Finance, Fundraising, Board } \\
\text { Members }\end{array}$ & $\begin{array}{l}\text { Financial and Corporate } \\
\text { Governance, Leadership, } \\
\text { Social Service }\end{array}$ & $\begin{array}{l}\text { Social, Technical, } \\
\text { Economic, } \\
\text { Environmental, } \\
\text { Political }\end{array}$ \\
\hline 1. & $\begin{array}{l}\text { Chief Counsel Healthcare } \\
\text { and Financial Institutions, } \\
\text { Board Member }\end{array}$ & $35+$ & $\begin{array}{l}\text { Corporate governance, } \\
\text { legal research, securities } \\
\text { regulation, many years of } \\
\text { executive-level banking } \\
\text { experience }\end{array}$ & $\begin{array}{l}\text { Multiple nonprofit board } \\
\text { representation actively } \\
\text { providing governance } \\
\text { and legal consultation }\end{array}$ & $\begin{array}{l}\text { Primary areas are } \\
\text { Social, Economic } \\
\text { and Political }\end{array}$ \\
\hline 2. & $\begin{array}{l}\text { CFO Healthcare Clinic, } \\
\text { Regional Hospitals, Board } \\
\text { Member }\end{array}$ & $30+$ years & Financial & $\begin{array}{l}\text { Financial and nonprofit } \\
\text { financial governance }\end{array}$ & $\begin{array}{l}\text { Economic and } \\
\text { Political }\end{array}$ \\
\hline 3. & $\begin{array}{l}\text { Partner Tax Accounting, } \\
\text { Board Member }\end{array}$ & $25+$ years & Corporate Audit/Finance & Finance & Economic \\
\hline 4. & $\begin{array}{l}\text { CEO Healthcare, Board } \\
\text { Member }\end{array}$ & $30+$ years & $\begin{array}{l}\text { Clinical therapy, corporate } \\
\text { leadership }\end{array}$ & $\begin{array}{l}\text { Nonprofit mission and } \\
\text { success }\end{array}$ & $\begin{array}{l}\text { Social, Technical, } \\
\text { Economic, } \\
\text { Environmental, } \\
\text { Political }\end{array}$ \\
\hline 5. & $\begin{array}{l}\text { Director Compliance } \\
\text { Healthcare Clinic, Board } \\
\text { Member }\end{array}$ & $25+$ years & Quality and Compliance & $\begin{array}{l}\text { Nonprofit } \\
\text { strategy/improvement }\end{array}$ & $\begin{array}{l}\text { Social, Technical, } \\
\text { Economic, } \\
\text { Environmental, } \\
\text { Political }\end{array}$ \\
\hline 6. & IT Manager & $15+$ years & $\begin{array}{l}\text { Nonprofit support, } \\
\text { IT management }\end{array}$ & Nonprofit Sustainability & $\begin{array}{l}\text { Social, Technical, } \\
\text { Economic, } \\
\text { Political }\end{array}$ \\
\hline 7. & Development Director & $10+$ years & Nonprofit fundraising & $\begin{array}{l}\text { Nonprofit } \\
\text { success/sustainability }\end{array}$ & $\begin{array}{l}\text { Social, Technical, } \\
\text { Economic, } \\
\text { Environmental, } \\
\text { Political }\end{array}$ \\
\hline 8. & $\begin{array}{l}\text { CEO Healthcare, Board } \\
\text { Member }\end{array}$ & $20+$ years & Corporate Leadership & $\begin{array}{l}\text { Financial and nonprofit } \\
\text { financial governance }\end{array}$ & Economic, Political \\
\hline 9. & $\begin{array}{l}\text { Sr Finance VP Healthcare, } \\
\text { Board Member }\end{array}$ & $30+$ years & Financial & $\begin{array}{l}\text { Financial and nonprofit } \\
\text { financial governance }\end{array}$ & $\begin{array}{l}\text { Economic and } \\
\text { Political }\end{array}$ \\
\hline 10. & Program Director & $20+$ years & Nonprofit Social service & Nonprofit social service & Social, Political \\
\hline 11. & Program Director & 17 years & Nonprofit Social service & Nonprofit social service & Social, Political \\
\hline 12. & $\begin{array}{l}\text { Human } \\
\text { Resource Director }\end{array}$ & 22 years & $\begin{array}{l}\text { Profit and Nonprofit HR } \\
\text { support }\end{array}$ & Social, Political & Social, Political \\
\hline 13. & IT Analyst & 10 years & $\begin{array}{l}\text { Profit/Nonprofit IT } \\
\text { support }\end{array}$ & Technical & Technical \\
\hline 14. & Medical Director & 35 years & $\begin{array}{l}\text { Profit/Nonprofit Social } \\
\text { support }\end{array}$ & $\begin{array}{l}\text { Social, Political, } \\
\text { Environmental }\end{array}$ & $\begin{array}{l}\text { Social, Technical, } \\
\text { Environmental } \\
\text { Political }\end{array}$ \\
\hline
\end{tabular}


Table 2. The summary and the contents of expert questionnaires.

\begin{tabular}{ccccc}
\hline & \multicolumn{4}{c}{ SRM Questionnaire Summary } \\
\hline Questionnaire \# & \# of Questions & Question Format & Questionnaire Objective & \# of Participants \\
Questionnaire 0 & 20 & Yes/No/Open Ended & SRM Framework Validation & 9 \\
Questionnaire 1 & 11 & 5 Point Likert Scale/Open Ended & SRM Planning Initiation/ Validation & 14 \\
Questionnaire 2 & 11 & 5 Point Likert Scale/Open Ended & SRM Planning Elements Validation & 11
\end{tabular}

Questionnaire 0: Category Summary and Sample Questions

SRM Framework Validation

Forecasting and Time Periods

Yes/No/Comment/Open-ended questions

1) Are the major lanes and sub-lanes representative of the dimensions/perspectives important for long term planning for SMNOs?

2) Is a roadmap important for your planning and policy-making that includes a planning timeframe?

3) Planning lanes extending to $20+$ years. Is 20 years the right target (Till 2040)?

4) Is it important to have the vision for each lane as part of this planning process? This includes "backward-looking as well as forward forecasting."

5) Definitions and Perspectives (refer to Table 3) STEEP (Social Technical Economic Environmental Political) Perspectives

Questionnaire 1: Category Summary and Sample Questions

SRM Determinants to Initiate a Strategic Plan

5 Point Likert Scale Questions: $1=$ not at all $2=$ some $3=$ moderately $4=$ strongly $5=$ extremely 1 Opened-ended Question

1) How important is it to have an initial strategic plan agreement before starting the process?

2) How much has the current Covid-19 scenario changed your need to implement a new strategic plan?

3) How important are key decision-makers in contributing and supporting a successful plan implementation?

4) How important is it to form a strategic planning team with key decision makers and process experts?

5) How important is leadership support to develop and implement a strategic plan?

6) How important is it that the strategic plan aligns with the decision-makers' authority?

7) How important is it to determine the organization's Strengths and Weaknesses?

8) How important is it to determine the organization's Opportunities and Threats?

9) Do you agree with the following statement: "It is best to develop a strategic plan after the initial agreement and decision-making team is firmly in place?"

10) How important is it to allocate adequate time for the decision-making team to develop and implement a strategic plan?

11) Please provide feedback regarding other necessary aspects of strategic planning implementation:

Questionnaire 2: Category Summary and Sample Questions

Correlation of elements in the SRM Framework to Figure 2 (Hierarchy of Strategic Road-Mapping Elements)

5 Point Likert Scale Questions: $1=$ not at all $2=$ some $3=$ moderately $4=$ strongly $5=$ extremely

1 Opened-ended Question

1) How much has the current Covid-19 scenario changed your need to implement a new strategic plan?

2) How important is it that an infrastructure assessment including, HR assessment, Technology, and New Business Models, be conducted as part of developing and implementing a strategic plan?

3) How important is it that Social perspectives such as health, cultural acceptance, employment, and mission be included in the infrastructure assessment to develop and implement a strategic plan? 


\section{Continued}

4) How important is an infrastructure assessment, including management and leadership development, and measurement, including data outcomes, be conducted?

5) How important are Technical perspectives such as data-driven analysis, continuous improvement, and social media input in the infrastructure assessment leadership support to develop and implement a strategic plan?

6) How important is it that funding assessment includes current financial practices, exploration of collaboration, and potential new funding opportunities?

7) How important are Economic perspectives such as meeting, sustaining, forecasting, and balancing programs, and planning to develop and implement a strategic plan?

8) How important are Environmental perspectives such as assuring environmental safety and health and wellness to develop and implement a strategic plan?

9) How important is it that governance includes a review of the mission, recruiting and orienting board members, and developing a board training plan to develop and implement a strategic plan?

10) How important are Political perspectives such as meeting organizational, government, and industry requirements, attaining political backing, and understanding regulatory risk to develop and implement a strategic plan?

11) Please provide feedback regarding other necessary aspects of strategic planning implementation in your organization.

The five perspectives of STEEP are considered the major roadmap lane. The roadmap sub-lanes form the criteria that compose the perspectives. The functions are critical elements of the criteria that define the functions. Tasks in the SRM framework were part of the case study that was used to help validate the framework. The time-based columns range from looking back two years to the present to five years into the future for the specific planning forecast. The 20 plus year vision column is not exacting and is used to formulate a theoretical long-term vision. Expert judgment determined that most SMNOs cannot forecast past the three to five-year future horizon given the level of uncertainty in these organizations' environments, so a five-year future forecast column was used. Multiple aspects of the STEEP perspectives cause the uncertainty. They may include dynamic social change, unexpected technological innovation, unforeseen good, and bad economic changes, or political changes that may change the regulatory environment.

Management in nonprofit organizations typically focuses on social aspects, specifically meeting the mission and staying on track for its vision. This differs from for-profit organizations that focus mainly on profitability and all aspects that lead to profitability. However, nonprofit organizations that measure their performance management have been known to make better decisions (Sanders \& McClellan, 2014). The use of recognized decision-making tools such as road-mapping, fills a gap area for nonprofit organizations, especially SMNOs. Table 3 defines the STEEP perspectives, while Table 4 depicts the SRM framework and includes the five STEEP perspectives. It is this SRM that forms the framework that is the proposed model to be uses in developing an SMNO strategic plan. The definitions were developed, starting with the literature review of multiple articles. The definitions were supplemented with expert feedback from the questionnaire process, adding to the taxonomy. 
Table 3. Taxonomy of strategic road-mapping perspectives for SMNOs.

\begin{tabular}{|c|c|}
\hline Perspective & Description \\
\hline SOCIAL (S) & $\begin{array}{l}\text { The social or sociological perspective is broadly the study of humans and their social interactions. This involves the ways } \\
\text { and means that these interactions shape communities and society. Here, society refers to the direct and indirect target } \\
\text { population or communities of interest. This perspective includes criteria or sub-criteria that have a significant positive or } \\
\text { negative impact on society. Social criteria may consist of 1) Health, 2) Cultural acceptance, 3) Employment, and } \\
\text { 4) Infrastructure and Operational effectiveness. Sometimes social and political perspectives are combined because the } \\
\text { boundaries are blurred. For this research, these two perspectives are separated. Criteria such as policies, regulations, and } \\
\text { other actions of policymakers are considered under the political perspective }\end{array}$ \\
\hline TECHNICAL (T) & $\begin{array}{l}\text { The technical perspective represents the point of view and priorities of technical managers, technologists, social workers } \\
\text { and clinicians, and others that may contribute that add value to the overall mission of the SMNOs. This perspective } \\
\text { incorporates the technologies, methodologies, and technical skills and considerations that enable SMNOS to remain } \\
\text { competitive and meet the mission's specific demands. For this strategic roadmap, the main criteria that make up the } \\
\text { technical perspective include 1) Data-driven and measured outcomes, 2) Continuous improvement and delivery, 3) } \\
\text { Business intelligence incorporates social media inputs as Instagram, Facebook, and Twitter, and 4) Infrastructure and } \\
\text { operational effectiveness. }\end{array}$ \\
\hline ECONOMIC (E) & $\begin{array}{l}\text { The economic perspective incorporates the cost of and financial sustainability of SMNO operations. The economic } \\
\text { perspective recognizes that SMNOs will not remain functional and meet its mission unless they can sustain their } \\
\text { financial viability. Criteria may include 1) Meet financial goal, 2) Future economic sustainability, 3) Financial forecasting, } \\
\text { planning, and monitoring, and 4) Balancing programs, resources, budgeting, accountability, and financial planning and } \\
\text { 5) Funding assessment. }\end{array}$ \\
\hline $\begin{array}{l}\text { ENVIRONMENTAL } \\
\text { (EN) }\end{array}$ & $\begin{array}{l}\text { The environmental criteria have an impact on the SMNO environmental culture and subsequent market impact. } \\
\text { Environmental criteria form a necessary foundation to maintain at the required level of functionality, allowing them } \\
\text { to meet mission demands. Criteria may include 1) Environmental safety and 2) Health and wellness. Often, local } \\
\text { community nonprofit organizations are located close to the population they serve to provide access and to assure cultural } \\
\text { acceptance. This may be in lower-income neighborhoods, so safety and cleanliness are criteria that must be confirmed as } \\
\text { well. }\end{array}$ \\
\hline POLITICAL (P) & $\begin{array}{l}\text { The political perspective criteria make up political motivation, policies, and regulations that represent the SMNOs } \\
\text { relating to the government or the public affairs of the area that govern the SMNO. Criteria may include 1) Meet } \\
\text { government or industry requirements, 2) Meet organizational policies, 3) Attain political backing, 4) Account for and } \\
\text { mitigate regulatory risk and, 5) Governance. Political and social perspectives may be intertwined, but their criteria must } \\
\text { be independent for this exercise. }\end{array}$ \\
\hline
\end{tabular}

Table 4. Small-Medium nonprofit organizations strategic road-mapping framework.

\begin{tabular}{|c|c|c|c|c|c|c|c|}
\hline Roadmap Lane & $\begin{array}{l}\text { Roadmap } \\
\text { Sub-Lane } \\
\text { Criteria }\end{array}$ & Functions & Tasks (Case Study Level) & $-2 \mathrm{Yr}$ & Present & $+5 \mathrm{Yr}$ & $\begin{array}{l}\text { Policy Vision } \\
(+20 \text { Years })\end{array}$ \\
\hline
\end{tabular}

S1:F1: Physical Well Being

S1: Health

S1:F2: Preventative Care

S1:F3: Mental Health Support

S2: F1: Cultural Diversity

S2: Cultural Acceptance

S2:F2: Cultural Inclusion

Social

S2:F3: Cultural Tolerance

S2:F4: Cultural Difference

S3: Employment S3.F1.: Paid Work

S4.F1.: Physical Support S4: F2:T1: Explore New

S4: Infrastructure and Mechanisms

Business Models

Operational Effectiveness S4:F2: Operational

Effectiveness

S4: F2:T2: HR Assessment 


\section{Continued}

S4: F2:T3: Management

Leadership Development

S4:F2: T4: Meeting

Organizational

Requirements

T1: Data-driven and

Measured Outcomes

T2: Continuous Improvement and Delivery

Technical T3: Social Media Input

T4: Infrastructure and Operational Effectiveness

Economic

E1: Meet Financial

Goals

E2: Financial

Sustainability

E3: Financial

Forecasting

and Planning

E4: Balance Programs,

Resources, and Financial

Planning

Assessment

E5:F2: Funding Monitoring

T1.F1: Data Collection

and Analysis

T1.F2: Artificial Intelligence

T2:F1: Routine Improvement

T2:F2: Break Through

Improvement

T3:F1: Social Networking

T3:F2: Business Intelligence

T4:F1: Physical Support

Mechanisms

T4:F2: Operational

Effectiveness

E1:F1: Financial Target

E1:F2: Debt Reduction

E1:F3: Sufficient Revenue

E2:F1: Business Success

E2:F2: Financial Obligations, Risks and Opportunities

E3:F1: Budgeting

E3:F2: Financial Outcomes

E4:F1: Financial Programs

E4:F2: Balancing Human capital

E5:F1: Funding Progress

E5: F1:T2: Identify New

Opportunities

E5: F2:T3: Assess Current

Practices

En1: F1: Environmental Policy

EN1: Environmental Safety

En1: F2: Safe Environment

En1:F3: Dangers

Environmental

EN2: Health

and Wellness

T4:F2: T1: Data and

Outcome Measurements

T4: F2:T2: Technology

Assessment

E5: F1:T1: Explore

Collaboration
En2:F1: Health Practices

En2:F2: Control Measures

En2:F3: Good Health 


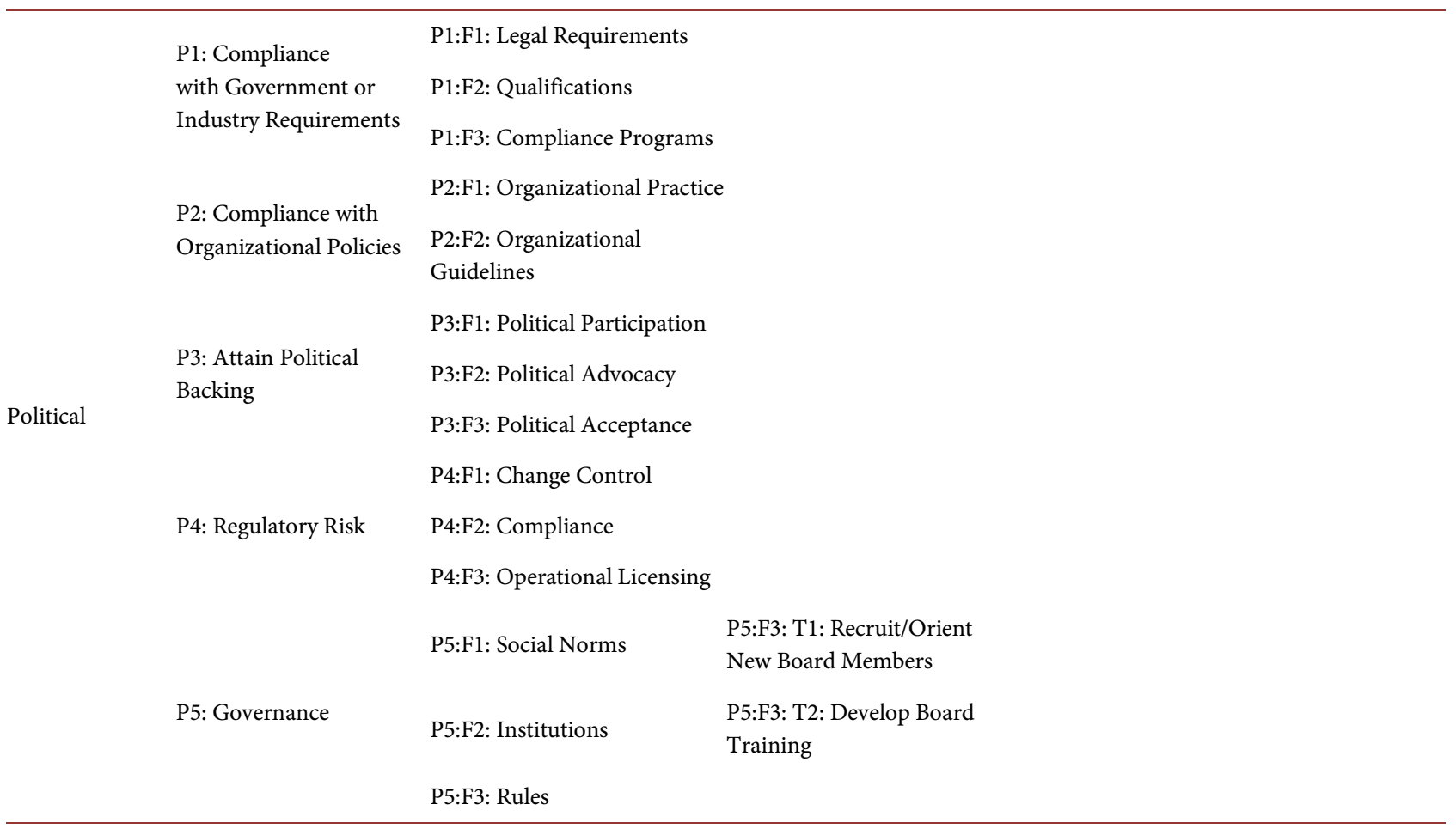

Each STEEP perspective may consist of multiple criteria that will address the SMNO system and structure. The STEEP perspectives form the roadmap lane and the sub-lane criterion, as depicted in Table 4. In turn, each criterion is composed of multiple functions that serve to provide an operational outcome. For the sake of this study, specific tasks were determined as part of the case study strategic planning process, as referred to in Figure 2. These elements are part of the SRM framework as depicted in Table 4.

\section{Results and Discussion}

The validation of this research relied on expert judgment relating to three separate sequential questionnaires. The questionnaires were sequenced to span from the initial SRM framework validation to the validation of strategic planning initiation determinants, and then finishing with expert judgment validation of the SRM elements that constitute the planning framework of the case study. It was necessary to develop each one of these questionnaires and then interpret the results. This interpretation was based on expert feedback along with correlating literature review.

- Questionnaire 0: SRM Framework Validation: Expert opinion and literature review were used:

Summary of the 20 questions in the questionnaire 0 :

1) The majority opinion does not go beyond five years for forecasting. This was based on the degree of uncertainty in forecasting nonprofit's future challenges. It was agreed that change is imposed by political and governmental fac- 
tors beyond the nonprofit's ability to forecast. With this rationale, the majority thought three years was the ideal future planning target, with five years as the limit of potential forecasting visibility.

2) The majority opinion was to leave vision planning in the framework. A 20 -year forecast period was originally prescribed in the SRM planning framework. Most experts rejected 20 years as a forecast because the uncertainty beyond 3 - 5 years was significant. However, when the 20 -year forecast was described as a theoretical time forecast that represents well beyond the current scenario, the experts agreed that the vision should be well into the future. This vision time frame creates a scenario that is far enough into the future where the planning team must project change that may be disruptive and form a strategy that must be considered relative to the current setting. It is useful to set long-term aspirations with shorter time period steppingstones (Phaal \& Muller, 2009).

3) A Healthcare CEO puts more weight on the Political perspective as an influencer. This expert with over 35 years of executive-level nonprofit experience acknowledged the importance of Social perspective understanding that the nonprofit organization must recognize and understand. It is here that most nonprofit organization's mission is created. However, the political aspect weighed down by social significance and government regulations, plays a significant role in influencing the nonprofit organization's planning pathway.

4) A SR Finance VP in Healthcare suggested combining 5-year Strategic Planning with Annual Business Planning. This high-level nonprofit expert leads planning and finance for a large nonprofit hospital. He argued that daily operational business planning should not be separated from longer-term strategic planning. He stated that the funding to implement the strategic planning must be derived from the operating budget that resides in the business plan that is short to intermediate in duration. Continuous planning and strategic planning are essential and highlight the need to ensure both are conducted in an organization (Suomalainen, Kuusela, \& Tihinen, 2015). Operational and budget planning are continuous planning, and strategic planning relies on ongoing operational planning to help fund its longer-term needs.

5) One CEO suggested broadening the health category to health and wellness, which the majority agreed with. Several other experts echoed this suggestion, and it was decided to expand the category since wellness is a process of becoming aware and making choices that affect health.

- Questionnaire 1-SRM Determinants to Initiate a Strategic Plan:

Summary of responses to the open-ended question \# 11 in Table 2 in Questionnaire 1:

1) Leadership must support the planning effort. Transformational leadership figures prominently in vision-based strategic planning and is more critical than transactional leadership (Moxley, 2004). Leadership should encourage diversity and knowledge holders in the strategic planning process. This creates an envi- 
ronment of open planning. The strategic plan's success depends on the proper planning team with transformational planning, not just doing what has always been done. Transformational leadership was shown to motivate employees (Breevaart et al., 2014). The implementation of the plan must have leadership support to ensure adequate resource deployment and measurable results.

2) Must have staff buy-in and input and overall employee engagement. Planning in nonprofit organizations can be difficult due to limited resources, competencies, and a lack of appropriate goals and measurements.

3) Proper communication is needed across an organization. Communication is a fundamental requirement of planning both for its development and implementation. It was determined that effective communication is critical for organizations to engage their employees and achieve objectives and strategies (Welch \& Jackson, 2007).

4) The SMNOs must be realistic in scope and planning duration. Plans that are too broad will have difficulty in their implementation. Plans too far into the future will have less accuracy due to more significant uncertainty of the longer time horizon.

The analysis of the responses to the Likert scale questions is obtained via Questionnaire 1 which focuses on the SRM Determinants to Initiate a Strategic Plan. The analysis of this questionnaire is provided in Figure 4.

Observation: Only Questions 2 and 9 had a mean value of less than 4 . The interpretation is that if the mean value is less than four than the experts did not consider it to be as significant as the other questions.

Question 2 (How much has the current Covid-19 scenario changed your need to implement a new strategic plan?)

An interpretation of this question is that the experts believe that the current Corona Virus pandemic has not diminished the need for strategic planning.

Question 9 (Do you agree with the following statement: "It is best to develop a strategic plan after the initial agreement and decision-making team is firmly in place?")

An interpretation of this question is that the experts may not want to delay the strategic planning process with too much formalization of an agreement that may hinder the planning and implementation process.

- Questionnaire 2-Case Study: Correlation of elements in the SRM Framework to the hierarchy planning level chart (Figure 3):

Summary of responses to the open-ended question \# 11 in Table 2 in Questionnaire 2:

1) There is a strong need to prioritize and assign appropriate resources. Resources, including financial, human, and appropriate infrastructure must be available. Many nonprofit organizations have programs tied to their mission. These programs must be resourced to accomplish their goals. Strategic planning is time-consuming and can require resources to which SMNOs have limited access to (Hu et al., 2014; Massie, 2000). 


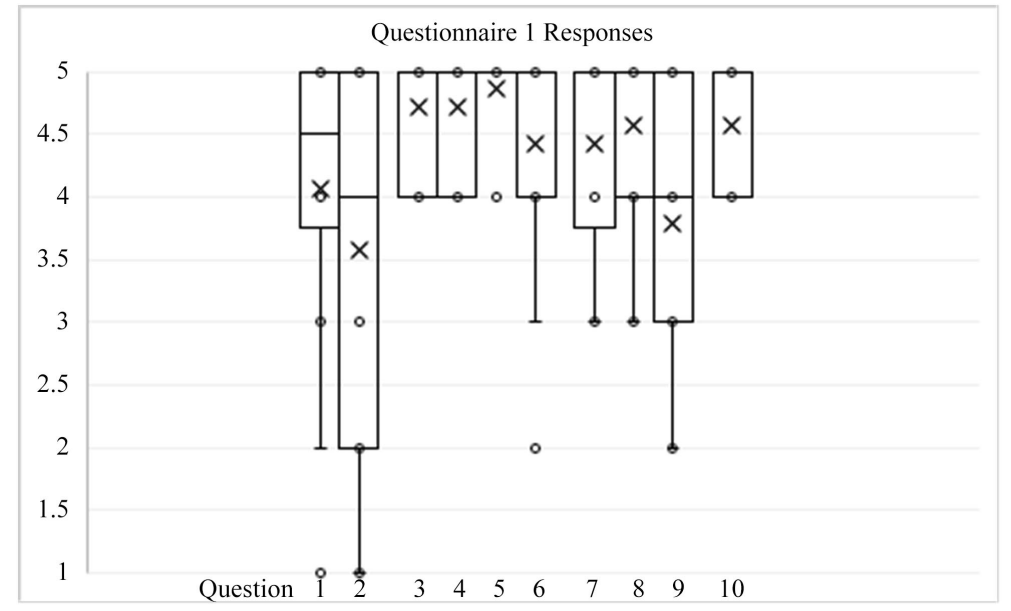

\begin{tabular}{ccccccccccc}
\hline Question & 1 & 2 & 3 & 4 & 5 & 6 & 7 & 8 & 9 & 10 \\
\hline Mean & 4.07 & 3.57 & 4.71 & 4.71 & 4.86 & 4.43 & 4.43 & 4.57 & 3.79 & 4.57 \\
Std. dev. & 1.27 & 1.60 & 0.47 & 0.47 & 0.36 & 0.94 & 0.85 & 0.76 & 1.05 & 0.51 \\
Median & 4.50 & 4.00 & 5.00 & 5.00 & 5.00 & 5.00 & 5.00 & 5.00 & 4.00 & 5.00 \\
Mode & 5.00 & 5.00 & 5.00 & 5.00 & 5.00 & 5.00 & 5.00 & 5.00 & 4.00 & 5.00 \\
Minimum & 1.00 & 1.00 & 4.00 & 4.00 & 4.00 & 2.00 & 3.00 & 3.00 & 2.00 & 4.00 \\
Maximum & 5.00 & 5.00 & 5.00 & 5.00 & 5.00 & 5.00 & 5.00 & 5.00 & 5.00 & 5.00 \\
\hline
\end{tabular}

Figure 4. The results of questionnaire 1.

2) Set realistic goals. Setting appropriate and realistic goals is critical for success. The goals are the outcome of proper planning and must be measurable. Goals must be properly targeted to key programs, and those programs should reflect the organization's vision and mission. Nonprofit leaders must keep their employees focused on challenging goals given their ever-changing environment and limited resources (Giffords \& Dina, 2004).

3) Assure appropriately trained and developed workforce. Training can be overlooked, especially with nonprofit organizations that are already lean, and in many instances, understaffed. However, the organization's success relies on having a healthy workforce, and this requires competent employees who are trained and developed to meet the needs of their clients. Nonprofits need and want training and development as long as the demand is consistent with their goals and needs (Levinson, 1987).

4) The model is relevant to the community that the respondents serve. Participants must represent the organization and the clients it serves, but open to growth in the proper areas. Strategic planning is perceived as necessary in community based small nonprofit organizations (Hu et al., 2014).

The analysis of the responses to the Likert scale questions are obtained via Questionnaire 2, which focuses on the correlation of elements in the SRM Framework to the hierarchy planning level chart. The analysis of this questionnaire is provided in Figure 5. 


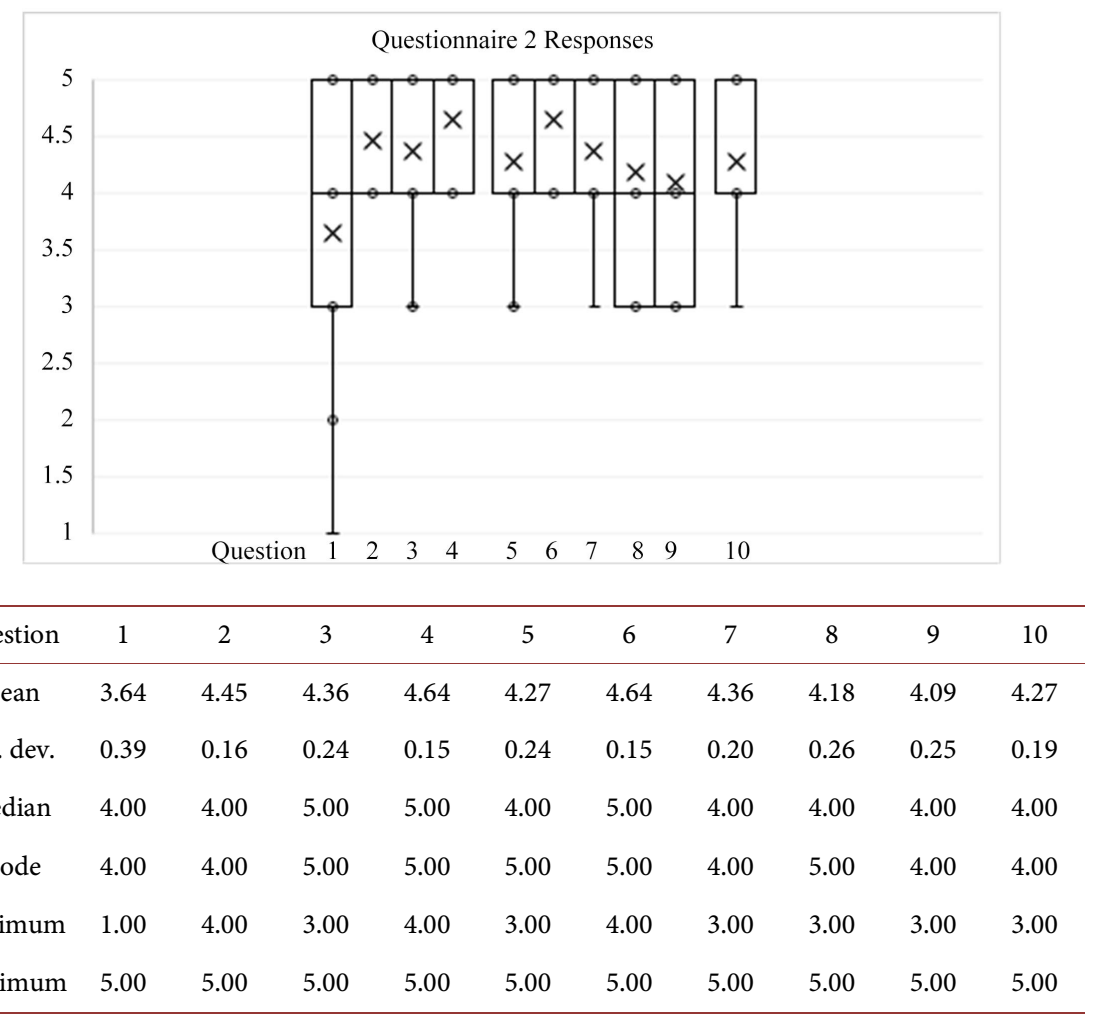

Figure 5. The results of Questionnaire 2.

Observation: Only Question 1 had a mean value of less than 4 . The interpretation is that if the mean value is less than four than the experts did not consider it to be as significant as the other questions.

Question 1 (How much has the current Covid-19 scenario changed your need to implement a new strategic plan?) An interpretation of this question is that the experts believe that the current Corona Virus pandemic has not diminished the need for strategic planning.

Table 5 summarizes the relationship of the questionnaires to the SMNO SRM validation process. The experts' judgments were used to validate each stage of the SRM research validation (Table 2). The three questionnaires had questions that were connected to the stage of validation in Table 2 and Figure 2. Knowledge of the SRM area developed the questions through expert judgment, literature review, and an SMNO case study that performed a planning process and developed elements and tasks at an implementation level.

\section{Conclusions and Recommendation}

The study presented a framework for a strategic roadmap applicable to an SMNO strategic planning process. Strategic planning and the execution that follows have been historically lacking in SMNO's due to limited resources and competencies necessary to execute such a plan. The use of recognized decision-making tools such as road-mapping fills a gap area for nonprofit organizations, especially SMNOs. A goal is for this model to facilitate the planning 
Table 5. Research questionnaire data evaluation summary.

\begin{tabular}{lll}
\hline $\begin{array}{l}\text { Questionnaire/ } \\
\text { Objective }\end{array}$ & Research Questions Connection to SRM & Summary \\
\hline Questionnaire 0 & $\begin{array}{l}\text { Expert research question answers validated the SRM framework by } \\
\text { their knowledge of SMNOs and their planning needs }\end{array}$ & This questionnaire validates the SMNO SRM creation \\
Questionnaire 1 & $\begin{array}{l}\text { Expert research question answers validated the planning } \\
\text { implementation needs by their knowledge of SMNO planning } \\
\text { processes }\end{array}$ & $\begin{array}{l}\text { This questionnaire validates the planning that is } \\
\text { necessary to initiate and implement an SMNO SRM. }\end{array}$ \\
Questionnaire 2 & $\begin{array}{l}\text { Expert research questions answers validated the planning elements } \\
\text { needed by their knowledge of SMNO and a specific case planning } \\
\text { application with specific tasks level planning usage }\end{array}$ & $\begin{array}{l}\text { This questionnaire validates elements at the planning } \\
\text { task level through a case study }\end{array}$ \\
\hline
\end{tabular}

process. Furthermore, the model focused on improving an SMNO health agency in Southern Connecticut.

This is the first study that applies high-level SRM modeling to SMNOs and as such, is a novel and effective approach to strategic planning. In this regard, a practical and scalable strategic planning framework that previously has not been available to the SMNO community is developed and utilized in conjunction with the Delphi technique. The proposed model is designed using an organization in Southern Connecticut as a case study. The CEO of the organization utilized the SRM in the Southern Connecticut agency to develop a strategic plan that met their organization's needs validating its effectiveness.

The questionnaire feedback was used to reach consensus to form decisions that validated each SRM process stage. The analysis of the questionnaire feedback created the final SRM model that was built upon a hierarchy of roadmap elements. From higher to more detailed, each level has been developed by the expert judgment that forms a framework for strategic road-mapping for SMNOs. Validated through expert judgment and a real-life case study, the SRM model is a valuable planning framework that SMNOs can implement for future planning regardless of their focus. The model is designed in a way that is suitable to become a permanent part of their planning processes assisting in maintaining their mission-based viability in the long term. Given that proper planning is the first step to sustain long-term viability, SRM based frameworks provide a visual and flexible way to make a more comprehensive assessment of the many variables to which an SMNO is subjected while it develops its mission.

It is worth mentioning that the study focused on a single mental health nonprofit organization in southeastern Connecticut. However, the flexible and versatile nature of the SRM model allows for usage in other SMNO organizations. Furthermore, despite that the experts had a deep and expansive experience, their nonprofit background was limited to several areas of experience with an emphasis on healthcare.

Future work should include further case studies that will provide increased evidence that an SRM is a viable strategic planning methodology for SMNOs. On a final note, SRM requires modification in each organization to address dynamic 
circumstances within the organization. The flexibility of the SRM allows each organization to adapt to its needs. There is a need for additional studies to perform SRM and to sustain committees to do such. This study was the first attempt to address this need.

\section{Conflicts of Interest}

The authors declare no conflicts of interest regarding the publication of this paper.

\section{References}

A., A. J., \& J., W. B. (1998). The Adoption of the Corporate Governance Model by Nonprofit Organizations. Nonprofit Management and Leadership, 8, 223-242. https://doi.org/10.1002/nml.8302

Abdel-Hamid, A. N., \& Hamouda, A. E. D. (2015). Lean CMMI: An Iterative and Incremental Approach to CMMI-Based Process Improvement. The 2015 Agile Conference, Washington DC, 3-7 August 2015, 65-70. https://doi.org/10.1109/Agile.2015.20

Brady, S. R. (2015). Utilizing and Adapting the Delphi Method for Use in Qualitative Research. International Journal of Qualitative Methods, 14, 1-6. https://doi.org/10.1177/1609406915621381

Breevaart, K., Bakker, A., Hetland, J., Demerouti, E., Olsen, O. K., \& Espevik, R. (2014). Daily Transactional and Transformational Leadership and Daily Employee Engagement. Journal of Occupational and Organizational Psychology, 87, 138-157. https://doi.org/10.1111/joop.12041

Bryson, J. M. (2010). The Future of Public and Nonprofit Strategic Planning in the United States. Public Administration Review, 70, s255-s267. https://doi.org/10.1111/j.1540-6210.2010.02285.x

Bryson, J. M., Eden, C., \& Ackermann, F. (2014). Visual Strategy: Strategy Mapping for Public and Nonprofit Organizations. New York: John Wiley \& Sons, Incorporated.

Chen, H., \& Kocaoglu, D. F. (2008). A Sensitivity Analysis Algorithm for Hierarchical Decision Models. European Journal of Operational Research, 185, 266-288.

https://doi.org/10.1016/j.ejor.2006.12.029

Dounos, P., \& Bohoris, G. (2010). Factors for the Design of CMMI-Based Software Process Improvement Initiatives. 2010 14th Panhellenic Conference on Informatics, Tripoli, 10-12 September 2010, 43-47. https://doi.org/10.1109/PCI.2010.46

Giffords, E. D., \& Dina, R. P. (2004). Strategic Planning in Nonprofit Organizations: Continuous Quality Performance Improvement-A Case Study. International Journal of Organization Theory and Behavior, 7, 66-80. https://doi.org/10.1108/IJOTB-07-01-2004-B004

Grant, J. S., \& Davis, L. L. (1997). Selection and Use of Content Experts for Instrument Development. Research in Nursing \& Health, 20, 269-274. https://doi.org/10.1002/(SICI)1098-240X(199706)20:3<269::AID-NUR9>3.0.CO;2-G

Gratton, P. C. (2018). Organization Development and Strategic Planning for Non-Profit Organizations. Organization Development Journal, 36, 27.

Harrison, T., \& Thornton, J. (2014). Too Many Nonprofits? An Empirical Approach to Estimating Trends in Nonprofit Demand Density. Nonprofit Policy Forum, 5, 213-229. https://doi.org/10.1515/npf-2014-0009

Hartman, F. T., \& Baldwin, A. (1995). Using Technology to Improve Delphi Method. 
Journal of Computing in Civil Engineering, 9, 244-249.

https://doi.org/10.1061/(ASCE)0887-3801(1995)9:4(244)

Hsu, C.-C., \& Sandford, B. A. (2007). The Delphi Technique: Making Sense of Consensus. Practical Assessment, Research, and Evaluation, 12, Article 10.

Hu, Q., Kapucu, N., \& O’Byrne, L. (2014). Strategic Planning for Community-Based Small Nonprofit Organizations: Implementation, Benefits, and Challenges. Journal of Applied Management and Entrepreneurship, 19, 83-101. https://doi.org/10.9774/GLEAF.3709.2014.ja.00007

Jarzabkowski, P., \& Kaplan, S. (2015). Strategy Tools-in-Use: A Framework for Understanding “Technologies of Rationality" in Practice. Strategic Management Journal, 36, 537-558. https://doi.org/10.1002/smj.2270

Kim, M. (2015). Socioeconomic Diversity, Political Engagement, and the Density of Nonprofit Organizations in U.S. Counties. The American Review of Public Administration, 45, 402-416. https://doi.org/10.1177/0275074013504616

Laurett, R., \& Ferreira, J. J. (2018). Strategy in Nonprofit Organisations: A Systematic Literature Review and Agenda for Future Research. VOLUNTAS: International Journal of Voluntary and Nonprofit Organizations, 29, 881-897.

https://doi.org/10.1007/s11266-017-9933-2

Lecy, J. D., Schmitz, H. P., \& Swedlund, H. (2012). Non-Governmental and Not-for-Profit Organizational Effectiveness: A Modern Synthesis. VOLUNTAS: International Journal of Voluntary and Nonprofit Organizations, 23, 434-457. https://doi.org/10.1007/s11266-011-9204-6

Levinson, D. (1987). Training and Development for Nonprofits. Training \& Development Journal, 41, 80-82.

Lewis, W. G., Pun, K. F., \& Lalla, T. R. M. (2006). Exploring Soft versus Hard Factors for TQM Implementation in Small and Medium-Sized Enterprises. International Journal of Productivity and Performance Management, 55, 539-554. https://doi.org/10.1108/17410400610702142

Linstone, H. A. (1981). The Multiple Perspective Concept: With Applications to Technology Assessment and Other Decision Areas. Technological Forecasting and Social Change, 20, 275-325. https://doi.org/10.1016/0040-1625(81)90062-7

Linstone, H. A. (2000). Decision Making for Technological Executives: Using Multiple Perspectives to Improve Performance [Review Reviews]. IEEE Transactions on Engineering Management, 47, 403-404. https://doi.org/10.1109/TEM.2000.865908

Linstone, H. A., \& Turoff, M. (2011). Delphi: A Brief Look Backward and Forward. Technological Forecasting and Social Change, 78, 1712-1719. https://doi.org/10.1016/j.techfore.2010.09.011

Maier, F., Meyer, M., \& Steinbereithner, M. (2016). Nonprofit Organizations Becoming Business-Like: A Systematic Review. Nonprofit and Voluntary Sector Quarterly, 45, 64-86. https://doi.org/10.1177/0899764014561796

Marc, L. (2001). Are We at the Cutting Edge or the Blunt Edge? Improving NGO Organizational Performance with Private and Public Sector Strategic Management Frameworks. Nonprofit Management and Leadership, 11, 247-270. https://doi.org/10.1002/nml.11302

Massie, M. C. (2000). A Strategic Planning Process for a Small Nonprofit Organization: A Hospice Example. Nonprofit Management and Leadership, 11, 211-223. https://doi.org/10.1002/nml.11206

Mihm, J. C. (2011). Expanded Visions for Today's Growing Governance Challenges. Public Manager, 40, 77-79. 
Moxley, D. P. (2004). Factors Influencing the Successful Use of Vision-Based Strategy Planning by Nonprofit Human Service Organizations. International Journal of Organization Theory and Behavior, 7, 107-132. https://doi.org/10.1108/IJOTB-07-01-2004-B006

Phaal, R., Farrukh, C. J. P., \& Probert, D. R. (2001). Characterisation of Technology Roadmaps: Purpose and Format. Portland International Conference on the Management of Engineering and Technology, Portland, August 2001, 367-374.

Phaal, R., Farrukh, C. J. P., \& Probert, D. R. (2004). Technology Roadmapping-A Planning Framework for Evolution and Revolution. Technological Forecasting and Social Change, 71, 5-26. https://doi.org/10.1016/S0040-1625(03)00072-6

Phaal, R., \& Muller, G. (2009). An Architectural Framework for Roadmapping: Towards Visual Strategy. Technological Forecasting and Social Change, 76, 39-49. https://doi.org/10.1016/j.techfore.2008.03.018

Phillips, J., Ruiz-Menjivar, J., Jones, J., \& Shoup, J. (2019). Establishing a 501(c)(3) Nonprofit Organization: An Overview. EDIS, 2019(2). https://doi.org/10.32473/edis-fy1481-2019

Saaty, T. L. (2008). Decision Making with the Analytic Hierarchy Process. International Journal of Services Sciences, 1, 83-98. https://doi.org/10.1504/IJSSCI.2008.017590

Sanders, M. L., \& McClellan, J. G. (2014). Being Business-Like While Pursuing a Social Mission: Acknowledging the Inherent Tensions in US Nonprofit Organizing. Organization, 21, 68-89. https://doi.org/10.1177/1350508412464894

Seyed Amir, B., \& Reiche, M. (2013). A Model for Sustainable Business Excellence: Implementation and the Roadmap. TQM Journal, 25, 331-346. https://doi.org/10.1108/17542731311314845

Skulmoski, G. J., Hartman, F. T., \& Krahn, J. (2007). The Delphi Method for Graduate Research. Journal of Information Technology Education: Research, 6, 1-21. https://doi.org/10.28945/199

Suomalainen, T., Kuusela, R., \& Tihinen, M. (2015). Continuous Planning: An Important Aspect of Agile and Lean Development. International Journal of Agile Systems and Management, 8, 132-162. https://doi.org/10.1504/IJASM.2015.070607

Sweis, R. J., Mahmoud Saleh, F. I., Dahiyat, S. E., Sweis, N. J., Saleh, R. A., \& Diab, H. (2016). Benchmarking of TQM Practices in INGOs: A Literature Review. Benchmarking, 23, 236-261. https://doi.org/10.1108/BIJ-02-2015-0013

Tenney, D., \& Sheikh, N. J. (2019). Development of a Strategic Roadmap Framework for Nonprofit Organizations: Literature Review. 2019 Portland International Conference on Management of Engineering and Technology (PICMET), Portland, 25-29 August 2019, 1-11. https://doi.org/10.23919/PICMET.2019.8893887

Topor, R., \& Boroiu, D. C. (2011). Nonprofit Organizations between Business and Uncertainty. Economics, Management and Financial Markets, 6, 595-601.

Welch, M., \& Jackson, P. R. (2007). Rethinking Internal Communication: A Stakeholder Approach. Corporate Communications: An International Journal, 12, 177-198. https://doi.org/10.1108/13563280710744847

Willyard, C. H., \& McClees, C. W. (1987). Motorola's Technology Roadmap Process. Research Management, 30, 13-19. https://doi.org/10.1080/00345334.1987.11757057

Wymer, W., \& Alves, H. M. B. (2013). Scale Development Research in Nonprofit Management \& Marketing: A Content Analysis and Recommendation for Best Practices. International Review on Public and Nonprofit Marketing, 10, 65-86. https://doi.org/10.1007/s12208-012-0093-1 